\title{
A liberdade de orientação sexual como expressão da dignidade: análise dos precedentes dos órgãos internacionais e regionais de proteção aos direitos humanos
}

\author{
Freedom to sexual orientation as expression of \\ human dignity: analysis of international and regional \\ human rights protection bodies' casework
}

Bruno Rodrigues de Almeida*

\section{Resumo}

O presente trabalho tem por escopo demonstrar como a dignidade do indivíduo abarca também o aspecto da liberdade à orientação sexual. Há precedentes reiterando que Estados soberanos estão obrigados a erradicar a criminalização do estilo de vida, assim como modificar as normas internas que impedem o acesso de homossexuais a certos direitos, postos e cargos. Percebe-se, entretanto, que devido ao forte antagonismo e rejeição institucional (principalmente na Assembleia Geral da Organização das Nações Unidas), o direito à vida familiar e afetiva dos indivíduos de orientação homossexual ainda não foi expressamente reconhecido, não obstante a constatação de importantes decisões mais progressivas por parte dos órgãos de proteção, como a Corte Europeia e a Corte Interamericana de Direitos Humanos.

Palavras-chave: Liberdade de orientação sexual. Dignidade humana. Direito Internacional dos Direitos Humanos. Direito a não ser discriminado. Direito à vida afetiva e familiar.

* Doutor em Direito Internacional pela Universidade do Estado do Rio de Janeiro. Mestre em Direito Internacional pela Universidade do Estado do Rio de Janeiro. Professor Adjunto de Direito Civil, Direito Internacional e Direito Ambiental Internacional da Universidade Federal Rural do Rio de Janeiro. Membro da ASADIP. Membro da SILADI. Advogado. Chefe do Departamento de Ciências Jurídicas do Instituto Multidisciplinar da UFRRJ. Nova Iguaçu - RJ - Brasil. E-mail: bra1278@gmail.com 


\section{Abstract}

This study aims to demonstrate how the right to sexual orientation is encompassed by the legal theory of human rights. According to precedents which have been rendered in international and regional levels of human rights protection, sovereign states must not only lift the criminalization of homosexual lifestyle, but also any kind of discriminatory rules or criteria preventing homosexuals from accessing certain rights, jobs or positions. However, due to strong antagonism and institutional rejection, (especially at the General Assembly of the United Nations) the recognition of the right to family and affective life to homosexuals is yet to be fully recognized, despite important precedents rendered by The European and the Inter American Courts of Human Rights.

Keywords: Freedom of sexual orientation. Human dignity. International Human Rights Law. Right to not be discriminated. Right to affective and family life.

\section{Introdução}

No dia 06 de junho de 2013, a Assembleia Geral da Organização dos Estados Americanos adotou a Resolução n 2807 (XLIII-O/13) sobre "Direitos humanos, orientação sexual e identidade de gênero", por meio da qual condena

todas as formas de discriminação contra pessoas devido à orientação sexual e à identidade ou expressão de gênero, e instar os Estados-membros, dentro dos parâmetros das instituições jurídicas de seu ordenamento interno, a eliminar, onde existirem, as barreiras que as lésbicas, gays e pessoas trans, bissexuais e intersexuais (LGTBI) enfrentam no acesso equitativo à participação política e em outros âmbitos da vida pública, bem como evitar interferências em sua vida privada.

Este é, sem dúvida, um grande marco institucional para a defesa dos direitos da minoria LGBT no âmbito do Direito Interamericano dos Direitos Humanos. No entanto, conforme será visto mais adiante, a Resolução AG OEA n² 2.807/2013 é uma vitória regional de reiteradas 
tentativas de certos Estados americanos de reconhecer mundialmente a liberdade de orientação sexual como direito humano que ainda sofre tremenda resistência na Assembleia Geral das Nações Unidas.

Sabendo que essa militância perpassa pela superação da configuração subjetiva clássica (meramente interestatal) da Sociedade Internacional, a consagração da dignidade do ser humano como valor axiológico da ciência jurídica e, consequentemente, do Direito Internacional contemporâneo, é preciso analisar com mais profundidade as decisões dos órgãos de proteção internacional dos direitos humanos para refletir acerca da situação perante o Direito Internacional dos Direitos Humanos.

Apesar de ter se consagrado após a década de 1950, a defesa de juridicidade inerente à dignidade humana não é uma construção iniciada exclusivamente a partir da Declaração Universal dos Direitos do Homem, podendo ser inclusive verificada bem antes dos acontecimentos do PósSegunda Guerra Mundial (DOLINGER, 2010, p.24). Seguindo a mesma linha de pensamento, Antônio Augusto Cançado Trindade (2002, p.3) afirma que, apesar do modelo interestatal de sociedade internacional consagrado a partir dos Tratados de Westphalia, bem antes da metade do século XVII já havia a noção de um Direito Internacional subjetivamente pluralista e com objetivo último de proteger o ser humano.

É bem verdade, entretanto, que as mudanças no cenário do sistema internacional contribuíram para a superação do paradigma westfaliano na contemporaneidade, possibilitando a reafirmação da personalidade jurídica do indivíduo no Direito Internacional por meio do resgate do caráter protetor da dignidade inerente à condição humana (TRINDADE, 2002, p.30).

De acordo com as lições de Antônio Celso Alves Pereira (2004, p.621), a evolução dessa conjuntura repercutiu diretamente na própria estrutura do Direito Internacional contemporâneo na medida em que este passou a ser percebido como o conjunto de normas e de instituições que têm como objeto reger a vida internacional, construir a paz e promover 
o desenvolvimento no intuito de buscar a realização da dignidade do gênero humano na sociedade internacional pós-moderna.

Muito embora já houvesse possibilidade do indivíduo reclamar a proteção de seus interesses perante certos órgãos internacionais desde 1929 pelo menos, é preciso ressaltar que essa dependia de certas condições políticas favoráveis, como a proteção diplomática, ou ainda nos casos de trabalhadores protegidos pelas Convenções da OIT. Portanto, este período pode ser encarado como estágio, de certo modo embrionário e bastante restrito, dos sistemas contemporâneos de proteção internacional dos Direitos Humanos (TIBURCIO, 2001, p.64).

Em processo complementar ao reconhecimento de um Direito Internacional com foco epistemológico na dignidade humana, consagrase uma nova dimensão da normatividade internacional que situa cada pessoa enquanto sujeito ativo, vinculando o Estado (outrora entendido como único sujeito capaz perante a sociedade internacional) ao respeito, garantia e realização dos direitos humanos consagrados no âmbito de tratados e convenções internacionais (PIOVEZAN, 2000, p.128).

Conforme ressalta Tatiana de Maekelt (2011, p.40), por meio da internacionalização da personalidade jurídica do indivíduo percebese a virada epistemológica na dinâmica da sociedade internacional contemporânea. Nela atuam conjuntamente os Estados soberanos, representados por seus respectivos corpos diplomáticos e consulares, as organizações internacionais e o próprio ser humano, atuando tanto individual quanto coletivamente (através de empresas transnacionais, organizações não governamentais e grupos de interesse para defesa dos interesses variados).

Deve haver, portanto, um binômio lógico e institucional marcado pela efetivação dos direitos internacionalmente reconhecidos - pelos Estados soberanos - e a proteção contra abusos eventualmente cometidos por quaisquer grupos a ser realizada perante certos organismos com atribuições jurisdicionais da Sociedade Internacional (TRINDADE, 2008, p.501). 
Reconhecer as transformações no Direito Internacional contemporâneo e o surgimento de outras esferas de proteção da dignidade humana, possibilitadas pela internacionalização dos Direitos Humanos, não significa diminuição da importância do Estado na efetivação dos direitos fundamentais, pois, na esteira do entendimento de David Bederman (2006, p.97), a experiência prática revela que, em termos da construção e da efetivação dos direitos humanos, ao invés de excludentes, o Direito interno e o Direito Internacional são, antes de tudo, complementares.

Ainda segundo Cançado Trindade (2011, p.321), o Sistema Internacional contemporâneo é marcado pela articulação de diferentes tipos de sujeitos atuando coordenadamente para a produção e aplicação de normas jurídicas do Direito Internacional, superando a teoria de que o Estado deveria ser o intermediário necessário entre o indivíduo e a ordem jurídica internacional.

Em decorrência do reconhecimento da fragilidade da pessoa humana ante a escalada da exclusão social, econômica e jurídica de grande parcela da população mundial, consagra-se a importância do Direito Internacional contemporâneo, subjetivamente reformulado e axiologicamente estruturado no valor da dignidade humana que

[...] não se dirige somente aos Estados soberanos, mas se projeta principalmente em função dos indivíduos da espécie humana, e, consequentemente, suas realizações no cunho da vida social como as organizações e negócios transnacionais (ALMEIDA; ROSADO, 2011, p.30).

\section{A convergência entre os ramos do Direito Internacional, a transnormatividade e o cosmopolitismo do Direito Internacional dos Direitos Humanos}

Os direitos previstos nos diplomas internacionais são tidos como fundamentais e estão presentes nas cartas políticas de muitos Estados. Para parte da doutrina que estuda o tema sob a perspectiva do 
Direito Constitucional Comparado, a eficácia dos direitos humanos não depende, ou tampouco se restringe, àquelas noções de direito "público" e "privado", pois, tendo em vista que o valor da dignidade (epicentro dos direitos humanos) se irradia para todas as relações jurídicas travadas na sociedade, pouco importa se o problema ocorre numa situação entre um indivíduo e uma entidade governamental ou entre dois particulares (SARMENTO, 2010, p. 236).

$\mathrm{Na}$ perspectiva de Phillip Jessup (1965, p.12), igualmente importante torna-se a constatação de que, a exemplo da integração entre os aspectos das relações de ordem pública e privada, há uma complementaridade lógica entre os ramos do Direito Internacional, especialmente porque nas situações transfonteiriças contemporâneas, normas e princípios classicamente atribuídos ao Direito Internacional Público e ao Direito Internacional Privado, além de se influenciarem mutuamente, atuam no intuito de garantir a realização de justiça no espaço transnacional.

Tais aspectos caracterizam o Direito Transnacional, cuja compreensão demanda dos juristas a superação da clássica dicotomia institucional e compartimentalizada das regras e princípios de Direito Internacional Público e do Direito Internacional Privado.

A constatação da transnacionalidade das relações jurídicas demonstra a reconfiguração dos padrões clássicos às necessidades sociais contemporâneas, suplantando a forçosa separação entre os ramos do Direito Internacional. O marco para essa nova aproximação entre Direito Internacional Público e Direito Internacional Privado é o resgate do ser humano como destinatário último das relações jurídicas que transbordam as fronteiras geográficas (ALMEIDA; ROSADO, 2011b, p.8).

Assim, esse Direito Transnacional abarcaria as regras e princípios do Direito Internacional Público e do Direito Internacional Privado, além de lidar com outras áreas dotadas de características híbridas como é o caso do Direito Marítimo, o desenvolvimento do Direito regional Europeu, a afirmação de um Direito Administrativo Global, os princípios e regras aplicáveis às empresas transnacionais, o Direito ao Desenvolvimento 
Econômico e a proteção dos direitos humanos (SCHACHTER, 1986, p. 878).

Com efeito, os tratados internacionais (em especial aqueles sobre direitos humanos) devem ser entendidos como excelentes veículos para a convergência dos ramos do Direito Internacional uma vez que promovem o transbordamento dos limites do direito local, fazendo com que as relações jurídicas passem a repercutir no contexto globalizado e multiconectado da contemporaneidade (BENDA-BECKMANN, 2005, p.4).

Para Alex Mills (2009, p.93), a confluência entre o Direito Internacional Público e o Direito Internacional Privado é decorrente da superação de dicotomias jurídicas reducionistas (interno/internacional, público/privado) e se dirige ao novo modelo de normatividade jurídica, o qual se projeta para além daquelas classificações da teoria jurídica do século XIX.

Didier Opertti Badán (2011, p.429), por sua vez, ressalta que essas evoluções no Direito Internacional contemporâneo são reflexos das próprias transformações experimentadas pelos atores do sistema internacional ao longo dos anos e requererá dos juristas o esforço para a maior aproximação institucional entre o Direito Internacional Público e o Direito Internacional Privado.

De acordo com Claudia Lima Marques (2011, p. 364), o valor axiológico dos direitos humanos se irradia do sistema internacional para os diversos segmentos dos ordenamentos jurídicos estatais, possibilitando que estes atuem como uma ponte entre o Direito Internacional Público e o Direito Internacional Privado. No mesmo sentido, segue lição de Nadia de Araújo (2008, p.14) para quem a superação do hiato hermenêutico entre os ramos do Direito Internacional em torno da dignidade humana é uma das tendências contemporâneas.

Portanto, a questão dos direitos humanos se coloca no âmago dessa normatividade transnacional, na medida em que os Estados, os organismos internacionais e os grupos de pressão do sistema 
internacional contemporâneo atuam em meio a essa nova realidade jurídico-fática.

Nesse sentido, Vicente Barreto (2008, p. 958) afirma que o enfrentamento dos problemas globalmente arraigados (tais como a redistribuição dos recursos, o agravamento da questão ambiental, a intolerância às diferenças e a violação dos direitos humanos das minorias) requer cada vez mais dos Estados soberanos (e do direito por eles produzido) uma reestruturação valorativa em torno da dignidade humana a fim de propiciar a construção de um cosmopolitismo jurídico.

Há muitos pontos de contato entre a teoria do Direito Transnacional e do Direito Cosmopolita, sobretudo no tocante à interatividade com o Direito Constitucional e na superação da dicotomia forçosa entre Direito Internacional Público e Direito Internacional Privado, com vistas à reorganização do espaço jurídico supranacional em torno da dignidade, pois, na medida em que haja articulação e cooperação dos sujeitos do Direito Internacional, os instrumentos jurídicos ali produzidos servirão como importantes indicadores para a aplicação dos regulamentos locais no intuito de alcançar a proteção da dignidade determinada no cenário supranacional (AGUIRRE, 2011, p. 343).

\section{Direito à liberdade de orientação sexual e o Direito Internacional dos Direitos Humanos}

A doutrina especializada afirma que o conceito teórico do direito humano à orientação sexual provém da conjuntura mais abrangente, os chamados direitos sexuais, cujo objetivo precípuo é eliminar aquelas políticas, práticas ou circunstâncias jurídicas que cerceiam a autonomia na condução da sua vida sexual, impõem vulnerabilidade em razão do gênero, restringem a liberdade na escolha dos parceiros sexuais, interferem na interação entre a vida sexual e a procriação, ou, ainda, estabelecem o condicionamento da plena aquisição e exercício de certos direitos e serviços públicos à adoção de um determinado padrão de sexualidade: 
Three concerns have dominated the sexual rights conversations globally (1) sexual autonomy and protection from sexual violence; (2) protection for sexual conduct in the context of reproductive sex, as well as rights to access contraception and abortion as an aspect of determining the meaning of sexual activity; and (3) freedom of sexual orientation, primarily the protection from discrimination on the basis of (homo)sexual orientation (ROSEMAN; MILLER, 2011, p. 323).

Do temário afeto aos Direitos à Orientação Sexual e à Identidade de Gênero, o presente trabalho abordará especificamente o tema da liberdade à orientação sexual no Direito Internacional dos Direitos Humanos, analisando como e em que medida tal prerrogativa é reconhecida como sendo inerente à dignidade humana.

Para efeitos didáticos, as etapas para o reconhecimento da liberdade de orientação sexual podem ser divididas em três estágios, a saber: a descriminalização das práticas sexuais consentidas entre indivíduos adultos do mesmo gênero, efetivação do direito à igualdade e a não discriminação por conta da sexualidade, e ainda aqueles direitos associados ao reconhecimento da vida afetiva e familiar independentemente da orientação sexual.

A criminalização da atividade sexual entre pessoas do mesmo gênero (leis de sodomia) somada ao padrão predominantemente heteronormativo de Direito resulta em acentuada assimetria ou mesmo na marginalização jurídica dos indivíduos cujos padrões de sexualidade destoem daqueles institucionalmente estabelecidos. No entanto, grandes avanços na militância em prol dos direitos dos homossexuais são alcançados a partir da identificação do tolhimento da liberdade sexual encontrados em diferentes ordenamentos jurídicos como violação dos direitos humanos (HELFER; MILLER, 1996, p.61).

O Direito Internacional dos Direitos Humanos é uma construção jurídica recentemente implementada, tendo sido inaugurado por um conjunto de seis diplomas internacionais: a Carta da ONU de 1945, a Declaração Universal dos Direitos do Homem de 1948, a Convenção 
Europeia sobre os Direitos do Homem de 1950, o Pacto Internacional sobre Direitos Civis e Políticos ${ }^{1}$ e o Pacto Internacional sobre Direitos Econômicos, Sociais e Culturais² ${ }^{2}$ ambos de 1966.

Conforme explica Eric Heinze (1995, p.11), quatro são os grandes objetivos da doutrina dos direitos humanos: i) articular a criação de instrumentos internacionais para o reconhecimento dos direitos considerados fundamentais; ii) identificar as violações desses direitos estabelecendo sanções aos violadores e, na medida do possível, buscar a reparação do dano; iii) criar as condições necessárias para a realização dos direitos humanos e, sobretudo, a prevenção de novas violações, iv) promover a educação da população por meio da discussão racional e pacífica.

Por tais motivos, o Direito Internacional dos Direitos Humanos seria o melhor foro para a discussão do problema contemporâneo da repressão institucionalizada às minorias sexuais, contribuindo para a conscientização da dimensão verdadeiramente globalizada do problema, além de propiciar uma plataforma política de grande expressão, o que permitiria levar a discussão para além dos cenários internos de cada país.

Não obstante, a estigmatização das minorias homossexuais se encontra de tal modo arraigada no ordenamento jurídico de muitos países que ainda hoje representa um obstáculo ao reconhecimento à condição de dignidade humana dos direitos inerentes à sexualidade dos indivíduos. Resulta desse quadro que, além das mesmas críticas tradicionalmente enfrentadas pela teoria dos direitos humanos (universalismo/relativismo, fragmentação, falta de precisão normativa, etc.) aplica-se ainda à liberdade de orientação sexual uma alegada falta

Resolução n 2.200-A da Assembleia Geral das Nações Unidas de 19 de dezembro de 1966. A eficácia jurídica desse diploma teve início com a adesão oficial de 35 Estados, ocorrida no ano de 1976. Aprovado pelo Congresso Nacional pelo Decreto Legislativo $n^{\circ} 226(1)$ de 12 dezembro de 1991 e promulgado no Brasil pelo Decreto $n^{\circ} 592$ de 6 de julho de 1992.

2 Resolução n 2.200 da Assembleia Geral da ONU de 19 de dezembro de 1966, aprovado pelo Congresso Nacional pelo Decreto Legislativo n 226 de 12 de dezembro de 1991, promulgado pelo Decreto n 591 de 6 de julho de 1992. 
de previsão específica no texto dos principais diplomas internacionais de direitos humanos (FELLMETH, 2008, p. 802).

Vê-se, desde logo, que o argumento acerca da falta de previsão de um direito à liberdade à orientação sexual nos tratados internacionais de direitos humanos não procede, uma vez que, pela simples análise dos diplomas, é possível chegar à conclusão de que este direito se espraia, na verdade, por todos os corolários básicos da dignidade humana: personalidade (autodeterminação), privacidade (respeito à intimidade, direito à vida familiar), liberdade (de opinião, de expressão, de associação, etc.) e igualdade (direito a não ser discriminado), valores que estão expressamente previstos nos principais diplomas internacionais sobre direitos humanos (LAU, 2004, p.1689).

\subsection{Descriminalização do estilo de vida}

A conscientização da questão da liberdade na orientação sexual enquanto corolário dos direitos humanos vem ganhando respaldo de outras áreas do conhecimento, principalmente por meio da decisão tomada pela Assembleia Geral da Organização Mundial de Saúde (OMS) em 17 de maio de 1990, retirando a homossexualidade do rol das doenças mentais elencadas na Classificação Internacional das Doenças $(\mathrm{CID})^{3}$.

Não obstante, era preciso mais do que a mera construção doutrinária para a consolidação do reconhecimento da liberdade de orientação sexual como um direito humano, e os primeiros avanços vieram a partir das decisões da Corte Europeia de Direitos Humanos nos casos Dudgeon vs. Reino Unido ${ }^{4}(1981)$, Norris vs. Irlanda ${ }^{5}(1988)$ e Modinos vs. Chipre (1993) ${ }^{6}$.

\footnotetext{
3 No Brasil, por meio da Resolução 001/1999, o Conselho Federal de Psicologia deixou de considerar a homossexualidade como doença, proibindo que psicólogos indicassem qualquer espécie de tratamento com o objetivo de alcançar uma "cura".

4 Julgado em 23 de fevereiro de 1981. European Human Rights Report Series A, no 45.

Julgado em 26 de outubro de 1988. European Human Rights Report Series A, nº 143.

Julgado em 22 de abril de 1993. European Human Rights Report Series A, n 259.
} 
Nesses três casos, aquela corte firmou entendimento de que legislações criminalizando a prática consentida de atos sexuais entre indivíduos adultos do mesmo gênero representa violação frontal ao artigo $8^{\circ}$ da Convenção Europeia dos Direitos do Homem (de 4 de novembro de 1950), o qual tutela o direito ao respeito pela vida privada e familiar:

Direito ao respeito pela vida privada e familiar

1. Qualquer pessoa tem direito ao respeito da sua vida privada e familiar, do seu domicílio e da sua correspondência.

2. Não pode haver ingerência da autoridade pública no exercício deste direito senão quando esta ingerência estiver prevista na lei e constituir uma providência que, numa sociedade democrática, seja necessária para a segurança nacional, para a segurança pública, para o bem-estar económico do país, a defesa da ordem e a prevenção das infrações penais, a proteção da saúde ou da moral, ou a proteção dos direitos e das liberdades.

Muito embora não se possa descartar a circunstância da limitação geográfica dos supramencionados precedentes da Corte Europeia, eles notadamente contribuíram para o fortalecimento do cenário jurídico internacional mais favorável ao direito à liberdade de orientação sexual, que seria mundialmente reconhecido com a decisão do Comitê de Direitos Humanos das Nações Unidas no paradigmático caso Toonen vs. Austrália?.

Nesse sentido, o Comitê decidiu que a criminalização da atividade sexual consensual entre dois homens adultos, estabelecida pelo Código Penal da Tasmânia, significava frontal violação ao art. 26 do Pacto Internacional sobre os Direitos Civis e Políticos:

Art. 26. Todas as pessoas são iguais perante a lei e tem direito, sem discriminação alguma, a igual proteção da lei. A este respeito, a lei deverá proibir qualquer forma de discriminação e garantir a todas as pessoas proteção

7 Comunicação n 488/1992. UN Doc./CCPR/C/50/488/1992. Julgada em 04/04/1994. 
igual e eficaz contra qualquer discriminação por motivo de raça, cor, sexo, língua, religião, opinião política ou de outra natureza, origem nacional ou social, situação econômica, nascimento ou qualquer outra situação.

No bojo da decisão, a justificativa do governo da Austrália para manutenção da legislação discriminatória como tentativa de contenção da propagação da AIDS foi prontamente rechaçada pelo Comitê de Direitos Humanos:

8.5 As far as the public health argument of the Tasmanian authorities is concerned, the Committee notes that the criminalization of homosexual practices cannot be considered a reasonable means or proportionate measure to achieve the aim of preventing the spread of AIDS/HIV. The Australian Government observes that statutes criminalizing homosexual activity tend to impede public health programmes 'by driving underground many of the people at the risk of infection'. Criminalization of homosexual activity thus would appear to run counter to the implementation of effective education programmes in respect of the HIVIAIDS prevention. Secondly, the Committee notes that no link has been shown between the continued criminalization of homosexual activity and the effective control of the spread of the HIVIAIDS virus.

Da mesma forma, o recurso aos valores éticos e morais não foi aceito, uma vez que poderia permitir que muitos Estados continuassem adotando medidas como aquelas verificadas na legislação penal tasmaniana:

8.6 The Committee cannot accept either that for the purposes of article 17 of the covenant, moral issues are exclusively a matter of domestic concern, as this would open the door to withdrawing from the Committee's scrutiny a potentially large number of statutes interfering with privacy. It further notes that with the exception of Tasmania, all laws criminalizing homosexuality have been repealed throughout Australia and that, even in Tasmania, it is apparent that there is no consensus as to whether Sections 122 and 123 should not 
also be repealed. Considering further that these provisions are not currently enforced, which implies that they are not deemed essential to the protection of morals in Tasmania, the Committee concludes that the provisions do not meet the 'reasonableness' test in the circumstances of the case, and that they arbitrarily interfere with Mr. Toonen's right under article 17, paragraph 1.

Diferentemente dos precedentes da Corte Europeia de Direitos Humanos, a decisão no caso Toonen baseou-se no direito à igualdade e não discriminação, obtendo impacto significativo no cenário internacional como importante argumento na militância em prol dos direitos dos homossexuais (SMITH; WILETTS, 2000, p. 49).

Veja-se ainda, por oportuno, a Resolução n 2002/36 do Comitê de Direitos Humanos da ONU sobre Execuções Extrajudiciais, Sumárias ou Arbitrárias $^{8}$, na qual se percebe a preocupação desta organização internacional com a perseguição e o assassinato de pessoas por conta da sua orientação sexual:

6. Reaffirms the obligation of Governments to ensure the protection of the inherent right to life of all persons under their jurisdiction and calls upon Governments concerned to investigate promptly and thoroughly cases of killings committed in the name of passion or in the name of honour, all killings committed for any discriminatory reason, including sexual orientation or racially motivated violence leading to the death of the victim, killings of persons for reasons related to their peaceful activities as human rights defenders or as journalists, as well as other cases where a person's right to life has been violated, all of which are being committed in various parts of the world, and to bring those responsible to justice before a competent, independent and impartial judiciary, and to ensure that such killings are neither condoned nor sanctioned by government officials or personnel.

$8 \quad$ De 22 de abril de 2002. 
A interação entre o direito internacional e o direito interno nessa questão pode ser comprovada pelo crescimento no número de países em várias partes do mundo que descriminalizaram práticas associadas à homossexualidade após as decisões da Corte Europeia de Direitos Humanos e do Comitê de Direitos Humanos das Nações Unidas.

No entanto, apesar da adequação do direito à liberdade de orientação sexual no Direito Internacional dos Direitos Humanos e das decisões dos órgãos dotados de jurisdição internacional, o reconhecimento dos direitos dos homossexuais pelas cortes nacionais tem sido, na maioria das vezes, justificados pelas normas internas em detrimento das fontes internacionais (FELLMETH, 2008, p. 824).

Isto significa que, apesar do Direito Internacional e do direito interno terem caminhado juntos para a descriminalização da homossexualidade, a grande maioria dos tribunais locais não reconheceu a premente necessidade pela modificação das suas legislações penais como proveniente das fontes jurídicas produzidas na Sociedade Internacional.

\subsection{Direito a não ser discriminado pela orientação sexual}

Os direitos inerentes à sexualidade do indivíduo não são violados tão somente pela legislação criminal ou execução sumária. Também a discriminação institucionalizada e a manutenção de padrões de sexualidade considerada "regular" ou "sadia", constante tanto em regras como nos critérios de certos ordenamentos jurídicos (heteronormatividade) contribuem para o alijamento dos direitos humanos de muitos indivíduos por conta da sua orientação sexual (MOSCHEL, 2009, p. 44).

O segundo estágio - direito à igualdade legal e a não ser discriminado por conta da orientação sexual - representaria, em tese, o fim das restrições impostas por autoridades públicas ou entidades privadas ao indivíduo por conta de aspectos intrínsecos à sexualidade.

A manutenção de padrões predeterminados de sexualidade no arcabouço jurídico dos ordenamentos estatais acaba por impedir o 
acesso de muitos indivíduos a muitos direitos considerados essenciais à condição humana de existência.

Por tais motivos, o Comitê dos Direitos Econômicos, Sociais e Culturais já afirmou reiteradamente nos Comentários Gerais sobre o direito ao trabalho, o direito à água e o direito à saúde que tais prerrogativas do ser humano são insuscetíveis a quaisquer formas de restrições discriminatórias, inclusive aquelas fundadas no gênero ou na orientação sexual dos indivíduos, violando o disposto no artigo 2.2 do Pacto Internacional de Direitos Econômicos, Sociais e Culturais (O'FLAHERTY; FISHER, 2008, p.215).

Corrobora-se tal entendimento por meio da interpretação dos Comitês de importantes convenções da ONU reiterando que diplomas internacionais sobre direitos humanos não se coadunam com a manutenção da discriminação com base na orientação sexual, tais como a Convenção Internacional dos Direitos da Criança, a Convenção para Eliminação de Todas as Formas de Discriminação contra a Mulher e a Convenção Contra Tortura.

Em Young vs. Australia, o Comitê de Direitos Humanos da ONU teve a oportunidade de analisar o tratamento jurídico da orientação sexual pelo viés da igualdade no acesso aos direitos e oportunidades. No caso em questão, tratava-se da recusa do governo australiano em conceder pensão ao parceiro sobrevivente de um servidor militar pelo fato dos dois serem do sexo masculino, em franca contraposição ao reconhecimento de direitos do indivíduo heterossexual nessas mesmas condições ${ }^{9}$.

Decisão semelhante foi prolatada pelo mesmo órgão no caso $X$ vs Colombia, corroborando o entendimento de que a concessão de certos direitos aos casais heterossexuais não unidos pelo vínculo matrimonial cria uma discriminação legal inconsistente com o artigo 26 do Pacto Internacional de Direitos Civis e Políticos. ${ }^{10}$

\footnotetext{
$9 \quad X$ vs. Colombia (Communication1361/2005), julgado em 30 de março de 2007.

$10 \quad X$ vs. Colombia (Communication1361/2005), julgado em 30 de março de 2007.
} 
Para parte da doutrina este precedente levou a questão ainda mais adiante do que no caso Toonen, pois o Comitê teria reconhecido a obrigação implícita dos Estados-partes do Pacto Internacional sobre Direitos Civis e Políticos de não restringir direitos por conta da orientação sexual (LAU, 2004, p.1701).

Em 17 de abril de 2003, durante a 59a Sessão do Comitê de Direitos Humanos das Nações Unidas, foi apresentada pelo Brasil (com o apoio de outros dezenove países) uma proposta para Resolução sobre os Direitos Humanos e a Orientação Sexual, na qual os Estados seriam instados a adotar em suas práticas e procedimentos de defesa dos direitos humanos medidas efetivas contra todas as formas de discriminação com base na orientação sexual ${ }^{11}$.

Caso fosse aprovado, tal instrumento permitiria que o Comitê monitorasse a situação da violação dos direitos humanos das minorias sexuais em todo mundo, bem como exigiria dos Estados um compromisso de adaptar seu direito interno. Infelizmente, a votação dessa proposta brasileira foi adiada seguidas vezes por força de articulações políticas (REDDING, 2006, p.437).

Em 2008, a Assembleia Geral da ONU permitiu a manifestação da Argentina (com apoio de 22 outros países, incluindo o Brasil) repudiando a discriminação com base na orientação sexual, reconhecendo que o ser humano tem direito à autodeterminação de sua sexualidade e de ser protegido contra agressões e perseguições por conta de sua orientação sexual. Mesmo que tal declaração seja desprovida de efeitos jurídicos análogos à Resolução do Comitê de Direitos Humanos, ainda assim serve como importante marco político (ROSEMANN; MILLER, 2011, p. 362 , nota 4).

Outros precedentes dos órgãos regionais de proteção aos Direitos Humanos também merecem destaque. Desde o final do século passado, a Corte Europeia de Direitos do Homem vem reiteradamente

11 E/CN.4/2003/L.92. 
afirmando que tanto a recusa para ingresso nas Forças Armadas quanto a demissão por conta da homossexualidade do indivíduo representam violação ao direito à privacidade, assim como previsto na Convenção Europeia de Direitos do Homem, revertendo seu próprio entendimento anterior $^{12}$.

A Comissão Interamericana de Direitos Humanos no caso Giraldo vs. Colombia ${ }^{13}$ considerou que a proibição de visitas íntimas à prisioneira lésbica poderia ser enquadrada como violação do direito à intimidade, previsto no art. 11 (2) do Pacto de São José da Costa Rica, muito embora este caso não tenha sido submetido à análise da Corte Interamericana de Direitos Humanos.

Pode-se considerar que tais decisões contribuíram para avanços no sentido do reconhecimento do direito à liberdade de orientação sexual como parâmetro para o tratamento igualitário e não-discriminatório no âmbito do Direito Internacional dos Direitos Humanos.

\subsection{Direitos à vida afetiva e familiar}

O terceiro estágio se caracteriza pelo movimento do direito de igualdade em direção à efetivação do direito à participação da vida familiar e comunitária das pessoas, independentemente da sua orientação sexual.

Compreende-se o reconhecimento jurídico do estilo de vida, por meio da tutela legal dos relacionamentos homoafetivos, e a legitimação dos homossexuais enquanto membros de uma unidade familiar plural, em que os direitos inerentes à autoridade parental não sejam restringidos por conta da orientação sexual.

Nesse diapasão, deve-se destacar que, além de polêmica, a questão da tutela legal dos relacionamentos homoafetivos não é

\footnotetext{
12 Lustig-Prean \& Beckett vs. United Kingdom, European Human Rights Report, v. 29, 1999, p. 548-553 , Smith \& Grady vs. United Kingdom; European Human Rights Report v. 29, 2000, p. 493-498, Perkins vs. United Kingdom (43208/98).

13 Caso n 11.656, Relatório n71/99.
} 
abordada de maneira homogênea pelos diversos ordenamentos, e isso já suscitou a manifestação de alguns órgãos internacionais.

O Comitê de Direitos Humanos da ONU decidiu no caso Joslin vs. New Zealand ${ }^{14}$ que a exigência da diversidade de gêneros para a celebração do matrimônio não representaria violação ao direito de igualdade previsto no art. 26 do Pacto Internacional Sobre Direitos Civis e Políticos:

8.2 The authors' essential claim is that the Covenant obligates States parties to confer upon homosexual couples the capacity to marry and that by denying the authors this capacity the State party violates their rights under articles 16, 17, 23, paragraphs 1 and 2, and 26 of the Covenant. The Committee notes that article 23, paragraph 2, of the Covenant expressly addresses the issue of the right to marry. Given the existence of a specific provision in the Covenant on the right to marriage, any claim that this right has been violated must be considered in the light of this provision. Article 23, paragraph 2, of the Covenant is the only substantive provision in the Covenant which defines a right by using the term 'men and women', rather than 'every human being', 'everyone' and 'all persons'. Use of the term 'men and women', rather than the general terms used elsewhere in Part III of the Covenant, has been consistently and uniformly understood as indicating that the treaty obligation of States parties stemming from article 23, paragraph 2, of the Covenant is to recognize as marriage only the union between a man and a woman wishing to marry each other.

8.3 In light of the scope of the right to marry under article 23, paragraph 2, of the Covenant, the Committee cannot find that by mere refusal to provide for marriage between homosexual couples, the State party has violated the rights of the authors under articles 16, 17, 23, paragraphs 1 and 2, or 26 of the Covenant.

14 Communication n 902/1999. Julgado em 17007/2002. 
9. The Human Rights Committee, acting under article 5, paragraph 4, of the Optional Protocol, is of the view that the facts before it do not disclose a violation of any provision of the International Covenant on Civil and Political Rights.

Aquele Comitê rejeitou o argumento de que o direito à igualdade legal culminaria em um direito ao casamento entre pessoas do mesmo sexo.

De fato, nenhum dos órgãos internacionais expressamente chegou a tal conclusão, mas há decisões importantes reconhecendo que o direito à vida familiar não pode ser restringido por conta da sexualidade do indivíduo.

Nesse sentido, a Corte Europeia de Direitos Humanos já teve a oportunidade de reconhecer que a homossexualidade não serve como justificativa à restrição do direito de guarda de um pai, como foi decidido no caso Mouta vs. Portuga/15. Não obstante, este mesmo Tribunal também já expressou entendimento de que o direito à vida familiar não significaria o mesmo que o direito a fundar uma família, motivo pelo qual não considerou haver afronta ao artigo 14 (proibição da restrição discriminatória de direitos) da Carta Europeia de Direitos Humanos no fato dos ordenamentos internos estatais permitindo que apenas os heterossexuais solteiros pudessem se candidatar à adoção ${ }^{16}$.

Em Schalk \& Kopf vs. Austria ${ }^{17}$, dois homens com residência habitual em Viena requereram, em 2004, a intervenção da Corte Europeia de Direitos Humanos, alegando que a proibição do casamento entre pessoas do mesmo sexo constante do Código Civil austríaco consistiria em afronta aos artigos 8 (direito à privacidade), 12 (direito ao casamento) e 14 (direito a não discriminação no gozo dos direitos) da Convenção Europeia dos Direitos do Homem.

Caso $n^{\circ} 33.290 / 96$, julgado em 12 de dezembro de 1999.

Caso Fretté v. France $n^{\circ} 3615 / 97$. Julgado em 26/05/2002.

Caso $n^{\circ} 30141 / 2004$. Julgado em 24/06/2010. A partir de $1^{\circ}$ de janeiro do mesmo ano entrou em vigor o Estatuto Austríaco das Parcerias Registradas. 
A decisão daquele órgão foi ao mesmo tempo consistente e inovadora em relação à sua jurisprudência anterior:

FOR THESE REASONS, THE COURT

1. Dismisses unanimously the Government's request to strike the application out of the Court's list;

2. Declares by six votes to one admissible the applicants' complaint under Article 12 of the Convention;

3. Declares unanimously admissible the applicants' complaint under Article 14 taken in conjunction with Article 8 of the Convention;

4. Declares unanimously inadmissible the remainder of the application;

5. Holds unanimously that there has been no violation of Article 12 of the Convention;

6. Holds by four votes to three that there has been no violation of Article 14 taken in conjunction with Article 8 of the Convention; [...].

Por um lado, a Corte reconheceu expressamente, pela primeira vez, que os relacionamentos homoafetivos constituem vida familiar, nos termos do art. $8^{\circ}$, além de reconhecer que o direito ao casamento previsto no art. 12 daquele diploma internacional não está mais limitado aos casais com diversidade de gênero. Não obstante, tal decisão estabeleceu ainda que os Estados-membros não estão obrigados a tutelar essa modalidade de vida familiar, seja pelo casamento seja por outros esquemas de registro, restando a análise sobre seu cabimento, modalidade e extensão à apreciação discricionária e soberana dos respectivos Poderes Legislativos:

Destaque-se desde logo a divergência da Corte no tocante à restrição do direito à vida familiar por conta da orientação sexual (art. $8^{\circ}$ c/c 14, CEDH) conforme votos vencidos dos Juízes Rozakis, Spielmann e Jebens:

The applicants complained not only that they were discriminated against in that they were denied the right to marry, but also - and this is important - that they did not have any other possibility of having their relationship 
recognised by law before the entry into force of the Act. We do not want to dwell on the impact of the Act, which entered into force only in 2010, and in particular on the question whether the particular features of this Act, as identified by the Court in paragraphs 18 to 23 of the judgment, comply with Article 14 taken together with Article 8 of the Convention, since in our view the violation of the combination of these provisions occurred in any event prior to the Act. Having identified a 'relevantly similar situation' (paragraph 99), and emphasised that 'differences based on sexual orientation require particularly serious reasons by way of justification' (paragraph 97), the Court should have found a violation of Article 14 taken in conjunction with Article 8 of the Convention because the respondent Government did not advance any argument to justify the difference of treatment, relying in this connection mainly on their margin of appreciation (paragraph 80). However, in the absence of any cogent reasons offered by the respondent Government to justify the difference of treatment, there should be no room to apply the margin of appreciation. Consequently, the 'existence or non-existence of common ground between the laws of the Contracting States' (paragraph 98) is irrelevant as such considerations are only a subordinate basis for the application of the concept of the margin of appreciation. Indeed, it is only in the event that the national authorities offer grounds for justification that the Court can be satisfied, taking into account the presence or the absence of a common approach, that they are better placed than it is to deal effectively with the matter. Today it is widely recognised and also accepted by society that samesex couples enter into stable relationships. Any absence of a legal framework offering them, at least to a certain extent, the same rights or benefits attached to marriage (see paragraph 4 of this dissent) would need robust justification, especially taking into account the growing trend in Europe to offer some means of qualifying for such rights or benefits. Consequently, in our view, there has been a violation of Article 14 in conjunction with Article 8 of the Convention.

Há opinião no sentido de que, embora a CEDH ainda não tenha reconhecido expressamente o direito ao casamento às pessoas do 
mesmo sexo, a identificação da vida familiar pode sinalizar aos Estadosmembros que estes devam criar regimes alternativos de registro para regular os relacionamentos homoafetivos (COOPER, 2011, p. 1763).

Já no âmbito do Pacto de San José da Costa Rica, dê-se destaque para o caso Atala Riffo y Ninãs vs. Chile, apresentado pela Comissão Interamericana de Direitos Humanos em 17 de setembro de 2010.

Segundo o relato da Comissão, a Suprema Corte do Chile negou o direito de guarda das filhas menores à mãe (que mantinha relacionamento amoroso com outra mulher) por entender que tal circunstância colocaria em risco a saúde mental das menores, o que violou uma série de princípios insertos na Carta Interamericana de Direitos, dentre eles: o direito à honra e à dignidade, o direito à igualdade e a não discriminação por conta da orientação sexual, o direito à proteção da vida privada e da vida familiar, assim como o direito das crianças em serem devidamente ouvidas nos assuntos da vida familiar que lhes interessem diretamente e outras garantias processuais ${ }^{18}$.

Na sentença, prolatada em 24 de fevereiro de 2012, a Corte Interamericana de Direitos Humanos entendeu que o comportamento do Estado chileno efetivamente violou os direitos da jurisdicionada à igualdade e a não discriminação por conta da orientação sexual, mas, reconheceu também, com base nos julgados da Corte Europeia de Direitos Humanos, que o direito à vida familiar também não pode sofrer ingerências arbitrárias das autoridades estatais por conta da orientação sexual do indivíduo ${ }^{19}$.

18 Caso Atala Riffo y Niñas vs. Chile. Sentença de 24 de Fevereiro de 2012, n³.

19 "176. En el presente caso, el Tribunal observa que desde noviembre de 2002 hasta la decisión de tuición provisoria, en mayo de 2003 (supra párrs. 41 y 42), existía un vínculo cercano entre la señora Atala, la señora De Ramón, el hijo mayor de la señora Atala y las tres niñas. Al respecto, la señora Atala manifestó que "éramos una familia absolutamente normal. Un niño, tres niñas, un gato, un perro, una perra, una casa, teniamos proyecto como familia. Teníamos sueños como familia". Además, la señora De Ramón declaró que "Il]a vida de los cinco miembros de la familia, seis [con ella] era muy cercana a lo idílico[, pues e]stablecieron una relación de mucha comunicación, al menos entre las mujeres de la familia".

177. Por tanto, es visible que se había constituido un núcleo familiar que, al serlo, estaba protegido por los artículos 11.2 y 17.1 de la Convención Americana, pues existía una convivencia, 
Percebe-se, portanto, que a Corte Interamericana, ao se reportar aos julgados da Corte Europeia sobre a matéria, acaba promovendo a transnacionalização do entendimento que o direito à vida familiar constitui parte do direito à liberdade de orientação sexual, fazendo com que se avance um pouco mais no reconhecimento desse terceiro estágio, alcançando agora o continente americano.

Não obstante, em termos mundiais, ainda se verifica a polarização em torno da questão na ONU, pois o número de Estados-membros que efetivamente alcançaram o terceiro estágio continua bastante inferior ao percentual daqueles cujos ordenamentos criminalizam e/ou ainda restringem os direitos dos indivíduos por conta da sua sexualidade. (ROSEMAN; MILLER, 2011, p.375).

Apesar da ferrenha resistência política verificada na Assembleia Geral da ONU, a doutrina entende que a consistência lógica na defesa dos direitos das minorias fragilizadas (religiosas, étnicas, raciais) representa - grande fundamento teórico que conduzirá ao reconhecimento internacional do direito humano à liberdade de orientação sexual em todas as suas dimensões. (FELLMETH, 2008, p.935).

Por tais razões, deve-se atentar para as conclusões do Relatório do Alto Comissariado das Nações Unidas para Direitos Humanos $(A C N U D H)$ sobre "leis e práticas discriminatórias e atos de violência com base na orientação sexual e identidade de gênero dos indivíduos", de 17 de novembro de 2011.

un contacto frecuente, y una cercanía personal y afectiva entre la señora Atala, su pareja, su hijo mayor y las tres niñas. Lo anterior, sin perjuicio de que las niñas compartían otro entorno familiar con su padre.

178. Este Tribunal ya concluyó que los fundamentos presentados tanto por la Corte Suprema de Justicia como por el Juzgado de Menores de Villarrica en la decisión de tuición provisoria constituyeron una medida inidónea para proteger el interés superior del niño (supra párr. 146), lo cual tuvo además como resultado la separación de la familia constituida por la madre, su pareja y las niñas. Ello constituye una interferencia arbitraria en el derecho a la vida privada y familiar. Por tanto, la Corte declara que el Estado vulneró los artículos 11.2 y 17.1, en relación con el artículo 1.1 de la Convención Americana en perjuicio de Karen Atala Riffo y de las niñas M., V. y $R$.. Respecto de éstas últimas, dichas violaciones a la vida familiar ocurren también en relación con el artículo 19 de la Convención, dado que fueron separarlas de manera no justificada de uno de sus entornos familiares." 
68. The Human Rights Committee has held that States are not required, under international law, to allow same-sex couples to marry. Yet, the obligation to protect individuals from discrimination on the basis of sexual orientation extends to ensuring that unmarried same-sex couples are treated in the same way and entitled to the same benefits as unmarried opposite-sex couples.

69. In some countries, the State provides benefits for married and unmarried heterosexual couples but denies these benefits to unmarried homosexual couples. Examples include pension entitlements, the ability to leave property to a surviving partner, the opportunity to remain in public housing following a partner's death, or the chance to secure residency for a foreign partner. Lack of official recognition of same-sex relationships and absence of legal prohibition on discrimination can also result in same-sex partners being discriminated against by private actors, including healthcare providers and insurance companies.

70. The Human Rights Committee has welcomed measures to address discrimination in this context. In its concluding observations on Ireland, the Committee urged the State party to ensure that proposed legislation establishing civil partnerships not be 'discriminatory of non-traditional forms of partnership, including taxation and welfare benefits.'

\section{Ao final do Relatório, é necessário atentar para as Recomendações aos Estados-membros da ONU, especialmente para o teor das alíneas (e), (f), (g) e (h):}

(e) Enact comprehensive anti-discrimination legislation that includes discrimination on grounds of sexual orientation and gender identity among prohibited grounds and recognizes intersecting forms of discrimination; ensure that combating discrimination on grounds of sexual orientation and gender identity is included in the mandates of national human rights institutions;

(f) Ensure that individuals can exercise their rights to freedom of expression, association and peaceful assembly in safety without discrimination on grounds of sexual orientation and gender identity; 
(g) Implement appropriate sensitization and training programmes for police, prison officers, border guards, immigration officers and other law enforcement personnel, and support public information campaigns to counter homophobia and transphobia among the general public and targeted anti-homophobia campaigns in schools;

(h) Facilitate legal recognition of the preferred gender of transgender persons and establish arrangements to permit relevant identity documents to be reissued reflecting preferred gender and name, without infringements of other human rights.

Saliente-se que este documento, embora não se revista do caráter vinculante de uma Resolução da Assembleia Geral da ONU, claramente reconhece a necessidade de que o corolário da igualdade jurídica precisa ser efetivamente alcançado em cada ordenamento, garantindo assim a progressiva eliminação das disparidades observadas por conta do tratamento discriminatório com relação à orientação sexual do ser humano.

\section{Conclusão}

Embora a Sociedade Internacional ainda requeira amadurecimento político para chegar ao terceiro estágio do reconhecimento do direito humano de liberdade à orientação sexual, as etapas posteriores (descriminalização do estilo de vida e proibição da discriminação por conta da sexualidade) efetivamente representam obrigações juridicamente fundamentadas para os Estados-membros da ONU.

Paralelamente, sistemas regionais de proteção, tanto no âmbito da Corte Europeia de Direitos Humanos como também na Corte Interamericana de Direitos Humanos, têm sido mais progressistas no reconhecimento da liberdade de orientação sexual, sobretudo com a adoção de normativas expressas como a Resolução AG/OEA n 2807, de 6 de junho de 2013, que expressamente reconhece, com base na Declaração dos Direitos Humanos, que todo ser humano tem direito à 
vida, à liberdade e à segurança de sua pessoa sem distinção de raça, sexo, idioma, credo ou qualquer outra.

Ainda assim, há opinião, no Comitê de Direitos Humanos da ONU, no sentido de que, apesar dos Estados não estarem obrigados pelo Direito Internacional a reconhecerem o direito dos indivíduos homossexuais ao matrimônio, pelo corolário da igualdade (art. 26, ICCPR) os direitos previstos internamente àqueles casais formados por homem e mulher não casados deveriam ser também estendidos aos casais do mesmo sexo em diversas áreas, tais como a prerrogativa dos alimentos, direitos sucessórios e também o direito do parceiro estrangeiro de residir no território nacional.

De outro giro, a falta desse reconhecimento legal por parte dos Estados resulta na marginalização dos indivíduos por conta da sexualidade e é reverberada pela conduta de setores privados, tais como os as companhias seguradoras ou de saúde complementar. Mesmo nos países onde se reconhecem direitos aos casais do mesmo sexo, seria desejável reforma legislativa para corrigir as eventuais discrepâncias no direito tributário e assistencial com vistas à eliminação da discriminação contra as minorias sexuais.

Em outras palavras, ainda que não seja pacífica a existência de um direito humano ao casamento entre pessoas do mesmo sexo, há que se concluir que a vida familiar é mais abrangente, motivo pelo qual outras formas de tutela legal são encorajadas. Não obstante, alguns aspectos do respeito à liberdade de orientação sexual já são reconhecidos no Direito Internacional dos Direitos Humanos, tanto no nível internacional quanto no nível regional, impondo aos Estados soberanos algumas obrigações, tais como: a eliminação das legislações criminalizando o estilo de vida, a repressão à violência contra as minorias sexuais, e a abolição das normas e práticas que resultem em tratamento discriminatório das sexualidades alternativas. 


\section{Referências}

AGUIRRE, Cecilia Fresnedo de. Los tratados de derechos humanos y su incidencia en el derecho internacional privado. In: ARROYO, Diego; MARQUES, Claudia Lima. Derecho internacional privado y derecho internacional publico: un encuentro necesario. Asunción: CEDEP e ASADIP, 2011. p. 337-344.

ALMEIDA, Bruno Rodrigues de; ROSADO, Marilda. A relação entre a globalização e o direito internacional privado. In: DEL'OLMO, Florisbal de Souza; KAKU, William Smith; SUSKI, Liana Maria Feix (Org.). Cidadania e direitos humanos: tutela e efetividade internacional e nacional. Rio de Janeiro: GZ, 2011. p. 15-35.

ALMEIDA, Bruno Rodrigues de; ROSADO, Marilda. A cinemática jurídica global: conteúdo do Direito Internacional Privado Contemporâneo. Revista da Faculdade de Direito da UERJ - RFD, Rio de Janeiro, v. 1, n. 20, 2011. Disponível em: <http://www.epublicacoes.uerj.br/index.php/rfduerj/article/viewFile/1516/1646>. Acesso em: 14 out. 2016.

ALMEIDA, Bruno Rodrigues de. 0 reconhecimento dos casamentos e das parcerias entre pessoas do mesmo sexo no direito transnacional: pluralismo, dignidade e cosmopolitismo das famílias contemporâneas. 2012. 367 f. Tese (Doutorado em Direito Internacional) - Rio de Janeiro: Universidade do Estado do Rio de Janeiro, 2012.

ANNONI. Danielle. Os novos conceitos do novo Direito Internacional. Rio de Janeiro: América Jurídica, 2002.

ARAUJO, Nadia de. Direito Internacional Privado: teoria e prática brasileira. 4. ed. Rio de Janeiro: Renovar, 2008.

BARROSO, Luís Roberto. Here, there, and everywhere: human dignity in contemporary law and in the transnational discourse. Boston College International and Comparative Law Review, Massachusetts, v. 35, p. 331-393, 2012. 
BARRETO, Vicente de Paulo. Globalização, direito cosmopolítico e direitos humanos. In: DIREITO, Carlos Alberto Menezes; PEREIRA, Antonio Celso Alves; TRINDADE, Antonio Augusto Cançado (Org.). Novas perspectivas do direito internacional contemporâneo: estudos em homenagem ao Professor Celso D. de Albuquerque Mello. Rio de Janeiro: Renovar, 2008. p. 941-960.

BEDERMAN, David. J. International law frameworks. 2. ed. Nova Iorque: Thomson West Foundation Press, 2006.

BENDA-BECKMANN, Franz Von; BENDA-BECKMANN, Keebet von; GRIFFTHS, Anne (Org.). Mobile People, Mobile Law: expanding legal relationships in a contracting world. Hants: Ashgate, 2005.

BOELE-WOELKI, Katharina; FUCHS, Angelika. Legal recognition of same-sex couples in Europe. Antuérpia: Intersentia, 2003.

BROWN, David. Making room for sexual orientation and gender identity in international human rights law: an introduction to Yogyakarta principles. Michigan Journal of International Law, Ann Arbor, v. 31, p. 821-879, 2010.

COOPER, Sarah Lucy. Marriage, family, discrimination and contradiction: an evaluation of the legacy and the future of the European Court of Human Rights' jurisprudence on LGBT rights. German Law Journal, Germany, v. 12, n. 10, p. 1746-1763, 2011.

DOLINGER, Jacob. Dignidade: o mais antigo valor da humanidade. os mitos em torno da declaração universal dos direitos do homem e da constituição brasileira de 1988. as ilusões do pós-modernismo/ pós-positivismo. a visão judaica. Revista do Direito Constitucional e Internacional, São Paulo, v. 70, p. 24-90, jan./mar. 2010.

FELLMETH, Aaron Xavier. State regulation of sexuality in international human rights law and theory. William and Mary Law Review, Williamsburg, v. 50, p. 796-935, 2008.

HEIZE, Eric. Sexual orientation: a human right. Londres: Martinus Nijhoff, 1995. 
JAKOBSEN, Janet R. Queer relations: a reading of Martha Nussbaum on same-sex marriage. Columbia Journal of Gender and Law, New York, v. 19, p. 133-178, 2010.

JESSUP, Philip. Direito transnacional. Trad. Carlos Ramires Pinheiro da Silva. Rio de Janeiro: Fundo de Cultura, 1965.

LAU, Holning. Sexual orientation: testing the universality of international human rights law. University of Chicago Law Review, Chicago, v. 71, p. 1689-1720, 2004.

LEE, Man Yee Karen. Equality, dignity and same-sex marriage. Leiden: Martinus Nijhoff, 2010.

LEONARD, Arthur S. The impact of international human rights developments on sexual minority rights. New York Law School Public Law and Legal Theory Research Paper, New York, n. 24, 2005. Disponível em: <http://ssrn.com/abstract=722124>. Acesso em: 20 abr. 2013.

MARQUES, Claudia Lima. Human rights as a bridge between private international law and public international law: the protection of individuals (as consumers) in the global market. In: ARROYO, Diego; MARQUES, Claudia Lima. Derecho internacional privado y derecho internacional publico: un encuentro necesario. Asunción: CEDEP e ASADIP, 2011. p. 352-376.

\section{MILLS, Alex. The confluence between Public and Private} International Law. Nova lorque: Cambridge University Press, 2009.

MÖSCHEL, Mathias. Germany's life partnerships: separate and unequal? Columbia Journal of European Law, New York, v. 16, p. 37-66, 2009-2010.

O'FLAHERTY, Michael; FISHER, John. Sexual orientation, gender identity and international human rights law: contextualizing the yogyakarta principles. Human Rights Law Review, Cary, v. 8, n. 2, p. 207-248, 2008. 
OPERTTI BADÁN, Didier. Derecho internacional público y derecho internacional privado. Hacia un diálogo renovado. In: ARROYO, Diego; MARQUES, Claudia Lima. Derecho internacional privado y derecho internacional publico: un encuentro necesario. Asunción: CEDEP e ASADIP, 2011. p. 429-448.

PEREIRA, Antônio Celso Alves. Soberania e Pós-Modernidade. In: BRANT, Leonardo Nemer Caldeira (Coord.). O Brasil e os novos desafios do Direito Internacional. Rio de Janeiro: Forense, 2004. p. 599-630.

PIOVEZAN, Flávia. Direitos humanos e o direito constitucional internacional. São Paulo: Max Limonad, 2000.

REDDING, Jeffrey A. Homosexuals and homo-sectuals: the international politics of sexuality, religion and law. Northwestern Journal of International Human Rights, Chicago, v. 4, n. 3, p. 436492, 2006. Disponível em: <http://www.law.northwestern.edu/jihr/v4/ n3/1/Redding.pdf>. Acesso em: 11 jun. 2015.

ROSEMAN, Mindy Jane; MILLER, Alice M. Normalizing sex and its discontents: establishing sexual rights in international law. Harvard Journal of Law and Gender, Cambridge, v. 34, p. 313-375, 2011.

SARMENTO, Daniel. Direitos fundamentais e relações privadas. 2. ed. Rio de Janeiro: Lumen Juris, 2010.

SCHACHTER, Oscar. Philip Jessup's Life and Ideas. American Journal of International Law, Washington, v. 80, n. 4, p. 878-895, 1986.

SMITH, Charlene; WILETS, James D. Lessons from the past and strategies for the future: international and comparative law to overturn sodomy laws. Seatle University Law Review, Seatle, v. 24, p. 49-77, 2000.

TRINDADE, Antonio Augusto Cançado. A pessoa humana como sujeito de direto internacional: a experiência da Corte Interamericana de Direitos Humanos. In: DIREITO, Carlos Alberto Menezes; PEREIRA, Antonio Celso Alves; TRINDADE, Antonio Augusto Cançado. Novas 
perspectivas do direito internacional contemporâneo. Rio de Janeiro: Renovar, 2008. p. 480-525.

TRINDADE, Antonio Augusto Cançado. The saga of the emancipation of the individual from his own state: thoughts on the historical recovery of the human person as subject of the law of the nations. In: ARROYO, Diego; MARQUES, Claudia Lima. Derecho internacional privado y derecho internacional publico: un encuentro necesario. Asunción: CEDEP /ASADIP, 2011. p. 315-335.

WINTEMUTE, Robert; ADENAS, Mads. Legal recognition of samesex partnerships: a study of national. Portland: Hart Publishing, 2004.

Recebido em: 15/10/2015

Aprovado em: 30/05/2016 